\title{
Student-oriented Examination in a Computer Architecture Course
}

\author{
Erik Larsson and Anders Larsson \\ Department of Computer Science, Linköpings Universitet, Sweden \\ \{erila, anlar\}@ida.liu.se
}

\begin{abstract}
Learning is a highly individual process. Some prefer learning by reading the course material, others learn best by listening to a lecture, while some like to learn in a trial-and-error way by themselves in a laboratory assignment. A good learning scheme is individual. A scheme that is good for some persons might not at all be good scheme for someone else. It is important to understand your own personal way to learn, but also when organizing a course individual learning alternatives should be acknowledged.

Examination in a course can be seen as a test occasion or as a learning occasion. Traditionally, examination has been an occasion where knowledge is tested. Written exams can be used to test the theory and laboratory work to test practical aspects of the course material. For laboratory work the distinction between learning and test of learning is somewhat unclear. The learning and the test of learning are mixed. However, in general, examination can be seen as an occasion to learn and/or to test knowledge.

We have, in a Computer Architecture course, taken the view that (1) learning is an individual process, and (2) that examination is a learning occasion. The consequence of our view $(1)+(2)$ is basically that examination should be individual, or student-oriented. Alternatives to traditional examination is also supported when taking gender, cultural, and age perspectives. We therefore developed two examination tracks where the students in the beginning of the course decided what track to follow. Common for both tracks is that credits are given that can be counted for in the written exam.
\end{abstract}

\section{Categories and Subject Descriptors}

C.1.0 [General]: Examination.

\section{General Terms}

Management, Performance, Experimentation.

\section{Keywords}

Examination, Learning, Indivudual Learning Process.

\section{Examination according to alternative 1}

The students write a report in groups of 2-3 students on an elective topic, such as "Power consumption in the XYZprocessor". The report is presented in the class where another student group acts as the opponents. The work is graded based on the report, the presentation and the opposition and the credits are included in the written exam.

\footnotetext{
Permission to make digital or hard copies of all or part of this work for personal or classroom use is granted without fee provided that copies are not made or distributed for profit or commercial advantage and that copies bear this notice and the full citation on the first page. To copy otherwise, or republish, to post on servers or to redistribute to lists, requires prior specific permission and/or a fee.

ITICS'04, June 28-30, 2004, Leeds, United Kingdom.

Copyright 2003 ACM 1-58113-836-9/04/0006_..\$5.00.
}

\section{Examination according to alternative 2}

The students, individually or in pair, define their own laboratory task related to a course topic such as cachememories or pipelines, solve the task and present the results in front of the class. Each student designs individually a multiple-choice pre-exam question (specifying what it tests, the question and correct answer). A student friend corrects the question and might improve it if needed. The teaching assistant selects questions for the multiple-choice pre-exam. Each student also creates individually one exam question, which a student friend corrects and if needed improves. Each part (lab. presentation, creation and evaluation of pre-exam questions, pre-exam, and creation and evaluation of exam question) is given credits that are included in the written exam.

\section{Discussion}

The idea with alternative examination is to give students the possibility to find their own best way to learn a topic. Also, we want to let the students feel more involved by allowing them to control their own learning process.

From learning point of view, we wanted to create assignments where students define the problems; and not only solving given problems. We had the feeling that students were used to be given fixed assignments to solve, and not to analyze and question what problem to solve and the impact of the solution. We also learned from previous years, where lectures and the report alternative were used, that students found it hard to grasp how it really worked in a processor. It was fine to understand the lectures but hard to transfer the theory to practice.

From student perspective, we believe, that an advantage is that examination is not fixed by the course leaders (lecturer and teaching assistant), making the student feel they have influence. The students received the idea with alternative examination with enthusiasm. Especially to create their own questions for the exam was something that thrilled them. However, the student found it extremely hard to define their own lab. assignments. The creation of exam questions learned the students that it is not trivial to make good questions.

From teachers perspective, we see a number of practical administrative advantages. For instance, by letting the students present their laboratory work instead of writing a report there is a saving of teacher's time since students control the quality by themselves. And for the lecturer, one difficult task is the creation of exam questions. However, we did not get as high quality questions as we expected. Finally, if all new questions are circulated among the students by the students themselves and they learn all questions prior to the exam, one may argue what is the value. On the other hand, the students actually learned the subject. And also, the exam is of course mixed with questions from the lecturer. We also learned that the learning perspective among students changes over the course. At the beginning there is a high interest to alternatives while at the end the main driving force is to pass the exam. 